\title{
The Assessment of Public-Private Partnership's Possibilities to Optimize Investments in Public Infrastructure
}

\author{
Linas Jasiukevicius ${ }^{1}$, Asta Vasiliauskaite ${ }^{2}$ \\ ${ }^{1}$ Kaunas University of Technology \\ K. Donelaicio st. 73, LT-44029, Kaunas, Lithuania \\ E-mail. linas.jasiukevicius@gmail.com \\ ${ }^{2}$ Mykolas Romeris University \\ Ateities st. 20, LT-08303, Vilnius, Lithuania \\ E-mail.avasil@mruni.eu \\ cross $^{\text {ref }}$ http://dx.doi.org/10.5755/j01.ee.29.1.19101
}

\begin{abstract}
This paper deals with an issue of how to evaluate the possibilities provided by the public-private partnership (PPP) to optimize investments in public infrastructure. Literature analysis discloses this process being complex in nature. Value for money (VfM) assessment is acknowledged as the main decision-supporting tool to assess whether to implement investment project (IP) as a PPP. However, due to its multifaceted nature, this process is challenging and demanding, while results can be very different depending on the approach and assumptions applied, which, in turn, also causes criticism on very PPP. To get reliable results, the rational public sector's comparator (PSC) model and the financially viable and affordable PPP model should be constructed as well as their rational comparison should be done. To satisfy these requirements, there is a need of rational comparative tools presenting complex approach to the VfM assessment. Accordingly, the main objective of the research was to create an integrated complex model of evaluating the possibilities provided by the PPP to optimize investments in public infrastructure as well as to assess its suitability to be used in solving issues related to this assessment. Theoretical background of the research was based on the scientific literature analysis, synthesis, comparison and generalization, while the model was created by using methods of statistical analysis, financial analysis and modeling and logical analysis. The model consists of five stages: 1) preparation of the initial IP; 2) selection of IP for the assessment of PPP; 3) PPP structuring and feasibility analysis; 4) VfM assessment of actual bids, and; 5) VfM monitoring, which includes ex-ante, actual and ex-post assessment. The model was assessed in the hypothetical case study, where its suitability to be used in solving the issues related to the assessment of PPP's possibilities to optimize investments in public infrastructure in both economic and social-based PPPs have been demonstrated. The results obtained allow arguing it as enabling to make reasoned decisions for the most efficient ways of IP implementation.
\end{abstract}

Keywords: Public-Private Partnership; PPP; Value for Money; Assessment; Public Investment Projects; Public Sector Comparator.

\section{Introduction}

Over the last two decades the policy shift towards market provision of infrastructure and services, traditionally considered as a domain of the public sector, shows increasing reliance on the private sector's provision, which can be seen in the rise of a broad spectrum of public and private sectors' cooperation forms widely adopted under the umbrella of 'Public-Private Partnership' (PPP). These public-private agreements can be different in respect of a level of the private sector's involvement in the provision of public infrastructure and services asserted by different numbers and combinations of transferred tasks to the private entities from simple management to complex agreements to design, finance, build, operate and maintain public infrastructure. Therefore, neither the concept of PPP, nor its definition is consensual. However, considering its main features, generally it can be described as a legally enforceable long-term (15-30 years) contract between the entities of the public and private sectors, based on which the provision of public infrastructure and services, traditionally provided by the public sector, is transferred to the private entity, from which investment (in the form of money, technology, expertise, reputation, etc.) is required in exchange of the possibility to collect revenues from the direct users or/and payments from the public sector by rationally allocating risks and benefits between both the public and private entities (partners).

Since the PPP is considered as the alternative way of public procurement and delivery of public infrastructure and services, it can be justified to be implemented only if there are reasoned arguments that the private entities can optimize investments in public infrastructure, i.e. can deliver a greater value and/or efficiency additional to those obtainable from purely public sector. Here optimization is considered as maximization of benefits the public sector can potentially get through alternative affordable ways of investments implementation, which, in turn, requires to analyze various possibilities of IP's implementation (Shaoul, 2005; Wang, 2014). The PPP may suggest a variety of benefits (Carbonara, Costantino, \& Pellegrino, 2014), however, it can also be stated that PPP is not a silver bullet. 
Therefore, in every case VfM of the PPP should be clearly demonstrated.

However, the assessment of PPP possibilities to optimize investments in public infrastructure is not without problems. Literature discloses many methodological issues in this field. Scientific discussions on this research topic are mostly concentrated on VfM assessment as its core element. However, neither the performance of this assessment, as such, nor the formation of rational comparative objects are sufficiently analyzed. It is mostly focused on several research aspects related to VfM assessment: disclosure of the importance of the best VfM achievement to the public sector, development of VfM assessment technique analysis of critical success factors important for VfM achievement and the identification of the problems related to the application of VfM approach. Regarding these aspects, the issues related to the formation of the optimal capital structure (Bednarek et al., 2012; Moszoro, 2010), determination of FDR (Ball, 2011; Evans, 2009; Grimsey \& Lewis, 2004), assessment and optimal allocation/sharing of risks (Abednego \& Ogunlana, 2006; Chung, Hensher, \& Rose, 2010; Gordon, Mulley, Stevens, \& Daniels, 2013; Hwang, Zhao, \& Gay, 2013; Jin \& Zhang, 2011; Ke, Wang, Chan, \& Lam, 2010), evaluation of non-financial benefits (NFBs) (Mota \& Moreira, 2015) and the difficulties of VfM assessment in dealing with uncertainty (Grimsey \& Lewis, 2005; Kokkaew \& Wipulanusat, 2014; Okmen \& Oztas, 2010; Tirelli, 2006) are mostly analyzed. As important factors for higher VfM achievement, it is also separately analyzed the problems related to the determination of a concession period (Bao, Peng, Ablanedo-Rosas, \& Gao, 2014; Carbonara et al., 2014; Hanaoka \& Palapus, 2012; Ng, Xie, Cheung, \& Jefferies, 2007) and encouragement of adequate incentives from the private sector through determination of appropriate payment and compensation mechanism (Takashima, Yagi, \& Takamori, 2010; Villalba-Romero \& Liyanage, 2016; Y. Wang \& Liu, 2015; Wibowo et al., 2012). However, most of these issues and aspects are analyzed only fragmentally as well as the attempts to apply an integrated systematic approach, including all abovementioned factors and aspects into consistent assessment, are very limited. There are no tools allowing to do complex assessment of PPP's possibilities to optimize investments in public infrastructure and make reasonable decisions for the most efficient ways of their implementation. There is a lack of studies characterized by the application of processoriented approach and disclosure of internal links between the key elements needed to be coherently evaluated to maximize VfM for the public sector in the PPP. Carbonara et al. (2014), Hanak \& Muchova (2015), Sarmento \& Renneboog (2016) state that sound assessment of the efficiency of public resources' use is one of the main challenges related to public investments.

Considering the above-presented problematic aspects, this article deals with the scientific problem of how to evaluate possibilities provided by the PPP to optimize investments in public infrastructure. Accordingly, the aim of this article is twofold. Firstly, it seeks to review methodological aspects of assessing PPP's possibilities to optimize investments in public infrastructure, based on which integrated complex model, enabling to perform this assessment, is created and presented. Secondly, based on the case study performed on the simulation of the hypothetical investment project (IP), the article seeks to assess the created model's suitability to be applied in solving the issues related to the above-mentioned assessment. The results could be useful for IPs' developers to make reasonable decisions for the most efficient ways for IPs' implementation.

The remaining part of the paper is organized as follows. Firstly, the main discussed theoretical aspects of the assessment of PPP's possibilities to optimize investments in public infrastructure are reviewed. The next part describes the created model enabling to carry out the complex assessment of these possibilities. The following part introduces the hypothetical IP, based on which the assessment of the model's suitability to be applied in solving issues related to the assessment of PPP's possibilities to optimize investment in public infrastructure is done. The paper is concluded in the last part.

\section{Theoretical Aspects}

As a process, the assessment of PPP's possibilities to optimize investments in public infrastructure includes the comparison of public infrastructure and services delivery options when this is done by implementing IP in the traditional way and as the PPP. VfM is widely recognized as a primary measure of PPP's benefit and is the main justification for choosing public or private financing to implement IP. As a concept, VfM emphasizes the objective to capture the best proportionality between obtainable value and incurred costs, that. In turn, discloses its relative nature (Ball, 2011). However, since the assessment for PPP's adoption is mostly focused on cost minimization, the VfM assessment is often considered as the systemic comparison of whole-life cost of IP when it is implemented by applying methods and means of government versus the private sector. As a result, VfM is usually measured using the concept of net present life-cycle costs (NPC) (Fernandes, Ferreira, \& Moura, 2015; Shaoul, 2005).

According to the general methodology, the standard investment appraisal consists of comparison of NPC of IP, implemented by using conventional procurement (CP) methods, known as the public sector comparator (PSC), with NPC of the same IP, procured as PPP with appropriate level of the private sector's involvement (Gouveia \& Raposo, 2012). Here, novel and herewith the most controversial feature of the technique is in respect of comparison that, besides expected ordinary net costs, costs related to appropriate IP's risks as well as other later presented elements are also included in the assessment. In PSC all risks are entirely assumed by the public procurement authority (PPA), while in contracting of PPP at least a part of risks, depending on PPP's form and scheme, are transferred to the private subjects (Martins, Marques, \& Cruz, 2011). According to net present value (NPV) rule, the option with the lowest NPC is selected as yielding the greatest benefit. VfM is calculated as a difference between NPC of the CP option and the PPP option. If NPC of the PPP option is lower than PSC, then PPP delivers VfM and therefore it can be approved to be implemented. 
The above-provided general principles of VfM assessment technique discloses the PSC being one of a key parameter allowing PPA to decide whether it is expedient to implement IP as PPP. In the process of comparison with outcome of competitive tenders it, as a ceiling on private firms' bids, enables to evaluate PPP's benefits by providing an aggregate estimate of its economic advantages or disadvantages (VfM). Therefore, the validity of decision for PPP's adoption depends on the reliability of PSC calculation and assumptions used more specifically. Complexity of IP's structure, insufficient or unreliable data, uncertainty in predicting IP's input variables, ranging from very specialized types of labor to energy and raw materials, of which lists can be quite long and it may not be obvious what the relevant market prices are or what the right amounts for some of these inputs should be used, even optimism bias, can bring a lot of subjectivity (Gouveia \& Raposo, 2012; Khadaroo, 2008; Moro Visconti, 2014). Since usually a long reference period of 20-30 years is used, even small changes in inputs highly effect final VfM results. Therefore, it is obvious that the estimates of PSCs can easy become a subject of controversy with accusations of being bias and not transparent enough.

There are many points of criticism on the PSC and herewith VfM assessment (Desgrees du Lou, 2012; Fernandes et al., 2015; Khadaroo, 2008), however, this also encourages various scientific discussions on the separate aspects and elements of VfM assessment. Accordingly, since PSC may consist of a sum of values of ordinary net cost, risks, competitive neutrality $(\mathrm{CN})$, nonfinancial benefits (NFBs) and transaction costs (TCs), the main disputes regarding assumptions used in the VfM assessment are related to: 1) whether the application of nominal or discounted cash flows' (CFs) technique should be used (Gordon et al., 2013; Marcelin \& Mathur, 2014; Martins et al., 2011; Maskin \& Tirole, 2008; Muller \& Turner, 2005; Shaoul, 2005); 2) if the discounting technique is used, whether the financial discount rate (FDR) closer to long-term government's borrowing rate or the approach of Capital Asset Pricing Model (CAPM) has to be used (Ball, 2011; Grimsey \& Lewis, 2004; Khadaroo, 2008; Moro Visconti, 2014; Shaoul, 2005); 3) how risks between the public and private subjects have to be allocated (Burke \& Demirag, 2015; Jin \& Zhang, 2011; N. Wang, 2014); 4) whether CN costs in respect of different levels of government has to be included in the assessment (Grimsey \& Lewis, 2005; Tsamboulas, Verma, \& Moraiti, 2013; Zhang \& Chen, 2013); 5) whether it is expedient to included NFBs in the assessment (Hellowell, 2013; Hwang et al., 2013; Liu, Love, Smith, Regan, \& Palaneeswaran, 2015; Mota \& Moreira, 2015; Ng, Wong, \& Wong, 2012; Parker \& Hartley, 2003; Silvestre, 2012; E. C. Wang, 2002; Zawawi, Ahmad, Umar, Khamidi, \& Idrus, 2014), as well as; 6) additional transactional costs (TCs) of PPP (Fernandes et al., 2015; Mota \& Moreira, 2015; Mu, Jong, \& Koppenjan, 2011; Sarmento \& Renneboog, 2016). Accordingly, literature is lacking solutions, which, by providing the systemized and integrated complex approach to assessment of the above-listed aspects, could increase openness and transparency of PSC structuring as well as very VfM assessment.
Beside PSC, the reliable VfM assessment also requires structuring the rational to compare PPP option, that, in turn, expands very assessment to wider assessment of PPP's possibilities to optimize investments in public infrastructure. This conceptually requires estimating whole life-cycle costs of the PPP option, either as proposed by the private bidder or constructed as the hypothetical shadow bid (SB) at the pre-procurement stage, which attempts to predict bidder's costs, financing structure and other assumptions. This is also not distinguishable from the assessment of such aspects as: 1) choice of a proper PPP's type (Batran, Essig, \& Schaefer, 2004; Hall, 2008), form and scheme; 2) optimization of capital structure (Moszoro, 2014; Zhang, 2005); 3) determination of mechanism of payment and compensation to the private subject; 4) assessment of risks retained by the PPA, and; 5) assessment of affordability of IP to be implemented as PPP in respect of PPA. (Gupta, Gupta, \& Agrawal, 2013; Moro Visconti, 2014; Shaoul, 2005; Y. Wang \& Liu, 2015). Moreover, since PPP, due to its complexity, is usually costlier in respect of transaction cost in comparison with $\mathrm{CP}$, the rationality of assessment primarily requires identifying IPs having PPP potential to justify relatively higher cost associated to this assessment.

When the PSC option and the PPP option are properly structured, VfM assessment can be performed, which may consist of both the qualitative and quantitative assessments, of which results are combined by using the multi criteria analysis (MCA) framework. The larger uncertainty with results of the quantitate assessment is, the more important the qualitative assessment becomes. This discloses the technique of VfM assessment being able to be flexible depending on the requirements. However, the quantitative assessment remains a fundamental part of the assessment of PPP's possibilities to optimize investments in public infrastructure. Considering features of the PSC and SB models, the VfM assessment mostly focuses on the comparison of the impact of estimated risk-adjusted cost elements on budget of PPA or the public sector, depending on the perspective the assessment is done. However, it is also rational to assess VfM for the users of public infrastructure and services, which are only fragmentary analyzed in literature. In general, scientific literature lacks for solutions, which could suggest the integrated complex approach to VfM assessment, integrating both assessment technique and preparatory actions enabling to perform this assessment for reliable results. Accordingly, the created complex integrated model, enabling at least partially to fill this gap, is presented in the upcoming section.

\section{The Model}

Considering the analyzed theoretical aspects, the created model of evaluating PPP's possibilities to optimize investments in public infrastructure in respect of assessment process can be divided into five the main stages (Fig. 1), which are as follows: 1) preparation of the initial IP; 2) selection of IP for assessment of its implementation as the PPP; 3) PPP structuring and feasibility analysis; 4) VfM assessment of actual bids, and; 5) VfM monitoring. The main aspects of the assessment in each stages are further presented accordingly. 
Stage 1. Since the assessment of PPP's possibilities to optimize investments in public infrastructure generally seeks to compare the $\mathrm{CP}$ option of public infrastructure and service delivery against the PPP option, among which the most beneficial for the public sector to proceed could be found, this primarily requires to construct the $\mathrm{CP}$ option, rational to compare against any other option with the appropriate involvement of private participation. This determines that the preparation of IP with the option, which offers the highest socio-economic benefit is a key ingredient for any further rational analysis for its possibilities to be implemented as PPP. Therefore, it requires a lot of efforts from PPAs to prepare it right.

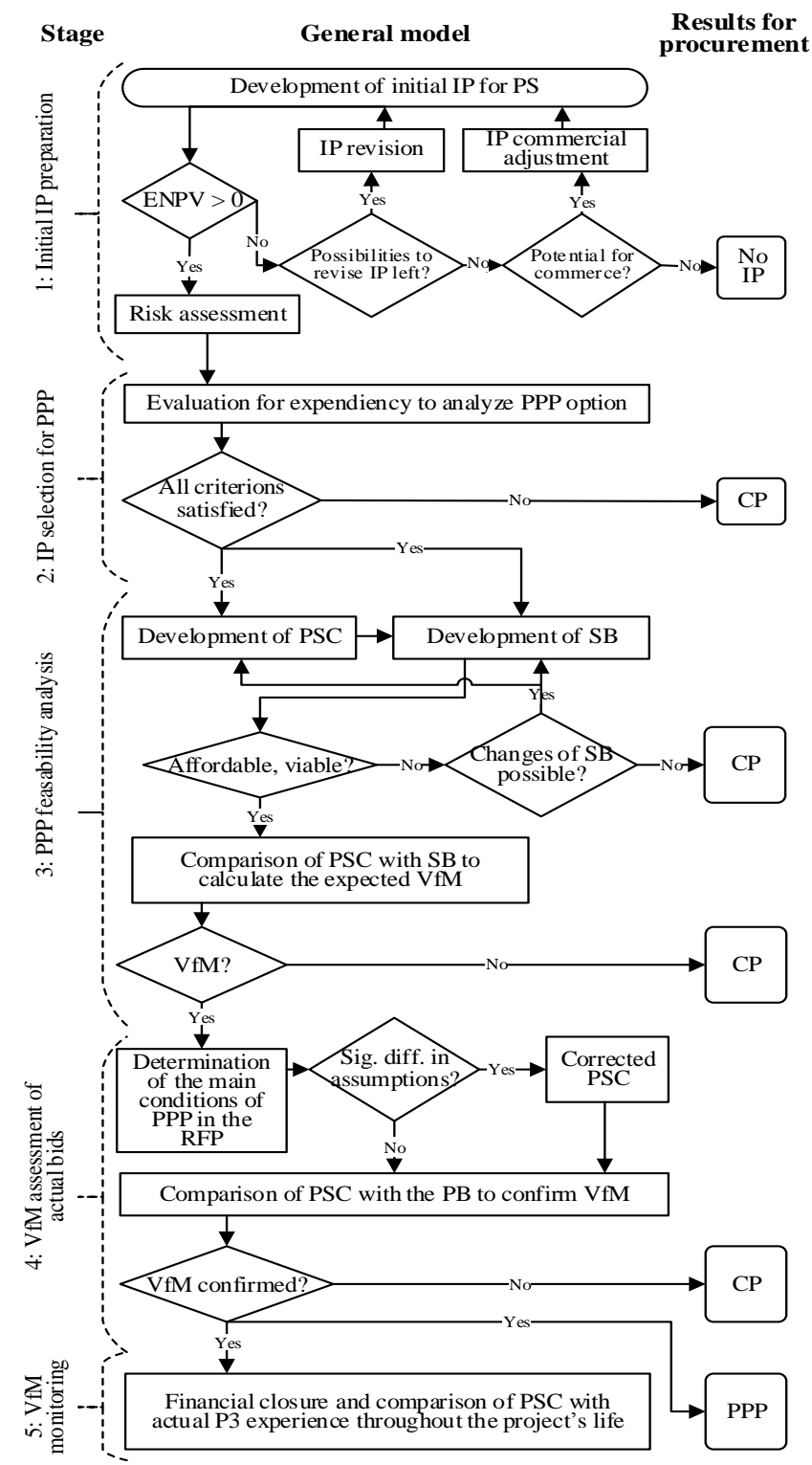

Figure 1. Scheme of the Model of Evaluating Possibilities of PPP to Optimize Investments in Public Infrastructure

Given the above-mentioned requirement, Cost-Benefit Analysis (CBA) or Cost Effectiveness Analysis (CEA) is usually used as a systematic approach for calculating and comparing all benefits and costs of possible to implement alternatives to assess the option providing the highest benefits. Both analytical frameworks refer to a list of underlying concepts, which is as follows (CPVA, 2014a;
European Commission, 2014b): 1) Opportunity cost; 2) Long-term perspective; 3) Monetary based, and; 4) Incremental approach. The integrated application of these concepts enables to prepare the IP allowing the PPA to assess the changes of welfare or only cost attributable to it. The initial IP is required to be prepared considering the standard framework of CBA, which consists of the following the main steps, which are as follows: 1) Description of IP's context; 2) Description of IP's content; 3) Option analysis; 4) Financial analysis; 4) Economic analysis, and; 5) Risk assessment. The option with the highest economic NPV (ENPV) or, in case of SEA, with the lowest costs, is rational to be selected as the most beneficial to implement and assess of its possibilities to be implemented as PPP.

Considering limitations found in literature, two specific solutions for improvement of the above-presented standard assessment technique are provided. First one, since FDR is critical point for results of the assessment, is for the determination of appropriate FDR. Depending on the approach, on the hand it can be equated to long-term government's borrowing rate. However, on the hand, if government seeks to implement new public management methods and increase involvement of the private sector in provision of public infrastructure and services, then there are more arguments to apply the CAPM-based approach. Considering Copeland (2014), Gözen (2013), Harvey (2005), the following formulas 1 and 2 for calculation of FDR for the developing and developed countries are suggested respectively.

$$
\begin{aligned}
& E\left(R_{i}\right)=R_{f}^{g}+0,6 \frac{\sigma_{l}}{\sigma_{g}}\left(R_{m a}^{g}-R_{f}^{g}\right)+R_{c} \\
& E\left(R_{\bar{i}}\right)=R_{f}^{g}+\operatorname{cor}\left(r_{h}, r_{g}\right) \frac{\sigma_{g}}{\sigma_{g}}\left(R_{m a}^{g}-R_{f}^{g}\right)
\end{aligned}
$$

here: $R_{f}^{g}$ - risk-free rate equated to rate of country's sovereign bonds denominated in one of global currency, $R_{\operatorname{ma}}^{g}$ average return of global market index, $R_{c}$ - country risk premium, $r_{l}-$ local market index return, $r_{g}-$ global market index return, $\sigma_{l}-$ standard deviation of local market index return; $\sigma_{g}$ - standard deviation of global market index return.

The second one is related to the assessment of investment cost overrun risk in the public IPs. Accordingly, to assess IP's risk, loglogistic 3P probability distribution with empirically-grounded parameters provided in the article of Jasiukevicius \& Vasiliauskaite (2015), is suggested.

Stage 2. Considering the conception and features of PPP, the following criteria can be distinguished to assess the expediency of IP to be fully analyzed for its implementation as PPP: 1) Requirement to invest in infrastructure; 2) Long-term demand of infrastructure and services; 3) Complexity of transferred services; 4) Possibility to measure outputs of services; 5) Possibility to allocate risks between the public and private partners; 6) Possibility to identify revenue streams to the private entity, and; 7) Interest from the private sector. All these criteria mostly scored only qualitatively (namely 'yes' or 'no') are equally important for a decision making whether it is worth to spend additional funds to carry out a complex analysis of PPP's possibilities to optimize investments in public infrastructure. Since they cover the main assumptions for 
successful PPP's structuring, to procced the assessment they should be positively assessed.

Stage 3. PPP structuring and feasibility analysis consists of three the main elements: 1) structuring of the PSC model; 2) structuring of the PPP model, and; 3) VfM assessment. Structuring of the PSC model primarily requires defining the appropriate scope of IP in respect of a number and scope of transferring tasks to the private entity, which would be considered as the procurement object of the PPP. Since there are many PPP's forms, among which the most suitable for IP's implementation has to be chosen, this process is iterative in nature. Considering a scope of PPP, the components of Raw PSC have to be identified, to which appropriate costs have to be assigned. The Raw PSC can comprise of various components from direct costs that can be assigned to certain service (direct capital costs, direct maintenance costs, direct operating costs, etc.) to indirect costs, of which occurrence are not directly related to the delivery of services (partial usage of administrative buildings, corporate and administrative overhead, etc.) (Formula 3).

$$
P S C_{R A W}=\sum_{t=0}^{t=n} \frac{I_{t}-R V_{n}-R E_{t}+O M_{t}+F A C_{t}+P C_{t}+P O C_{t}}{(1+r)^{t}}
$$

here: $C F$ - cash flow, $r$ - discount rate, $I$ - investments, $R V-$ residual value calculated at the end of the reference period, $O M$ operating and maintenance costs, $R E$ - revenue, $F A C$ - financing arrangement costs, $P C$ - procurement costs, $P O C$ - public oversight costs.

To compare rationally against PPP, the PSC model requires to include risk value, which is a product of losses, $L$, of individual risk events, $i$, and probability of loss occurrence, $p(L)$.

$$
\text { Risk }=\sum_{i} L_{i} p\left(L_{i}\right)
$$

A traditional approach to the risk assessment primarily suggests to identify relevant risk factors (RFs) (Lehtiranta, 2014). Then, it is estimated potential losses and probabilities of their occurrence, based on which values of risk can be calculated. However, when this technique is used, the reliability of results highly depends on whether RFs are independent from each other, i.e. the occurrence of one RF can affect the occurrence of other RF, that is difficult to avoid in most of cases. The longer a list of RFs is included in the quantitative assessment, the more is difficult to avoid double counting that, in turn, may result in overestimation of IP's risk. Considering this issue, it is suggested the inverse approach to risk assessment, of which the main principles can be explained as follows. First, probability distributions (PDs) reflecting tendencies of possible cash flows' (CFs) changes of the estimated values have to be applied to all direct CFs to calculate risk estimates (REs). Second, each of REs has to be assigned to one of the appropriate risk groups (RGs), in which they also have to be summarized. Finally, the values of RGs have to be divided equally into relevant RFs identified in the appropriate RGs.

In total, 8 RGs are identified: legal, political, force majeure, market, operation, design, construction, economic and residual value. All these RGs have to be allocated between the public and private partners depending on which of the parties can manage them at least costs. Figure 2 presents the created model of risk allocation between the public and private entities in the PPPs. According to this model, risk can be divided into two major groups: nonfinancial risk and financial risk. The former includes legal, political and force majeure RGs, for which, since they do not depend on direct actions of project promoters, REs are not calculated and, therefore, they are not included in the PSC model and are foreseen only in the PPP contract. Since political risks are related to the government's actions, it is preferable to allocate this RG to the public sector. Legal risks in the scope of government's or PPA's actions are usually assumed by the PPA. However, legal consequences associated with failures of the private entity to fulfil their obligations have to be transferred to the private entity. Force majeure risks, since they are above the abilities of both parties to manage them, are usually preferred to be allocated equally among the parties.

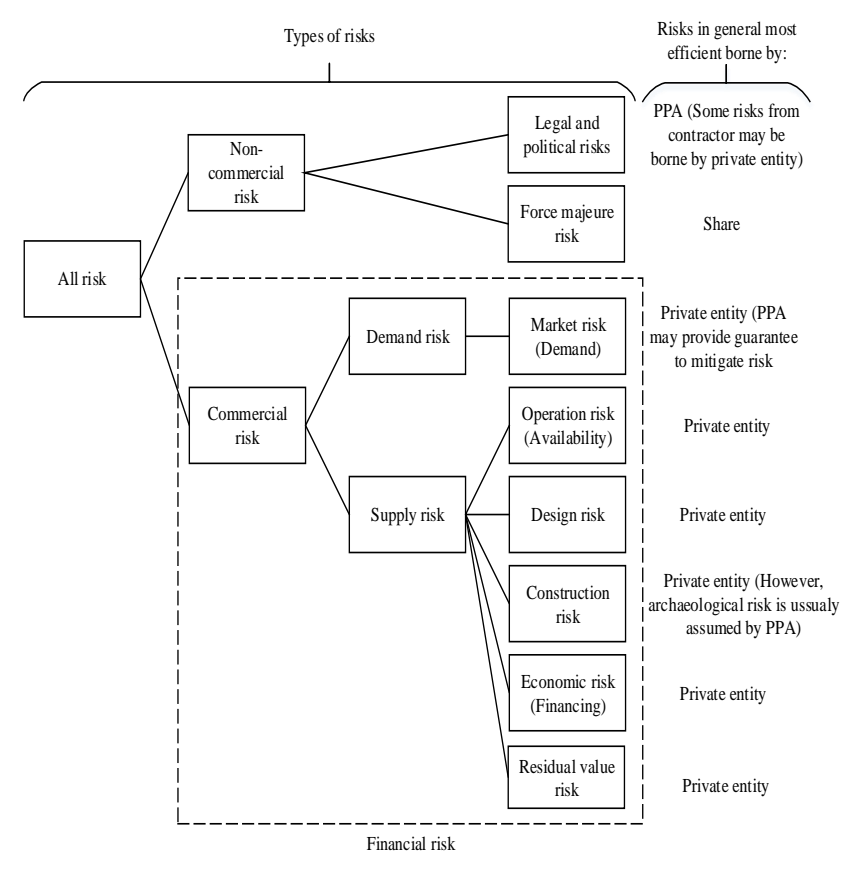

Figure 2. Risk Allocation in the PPP

The latter major group is comprised of risks directly related to IP's implementation and service delivery and, therefore, are assessed quantitively by estimating REs and including them as costs in the PSC model. It is comprised of market, availability, design, construction, financing and residual risks, which, to encourage IP's efficiency in respect of whole life costing, are preferable to be mostly transferred to the private entities. The exemption is the market risks, which, depending on how much guarantees are provided from the PPA to the private entity, also can be partially or fully assumed by the PPA, that, in turn, determines whether the socially-based or economic-based PPP can be chosen. Archaeological risk, although it is a part of construction RGs, is also preferable to be allocated to the public sector, since a site of construction is usually chosen by the PPA. 
When risks are allocated between the parties, Maximum financial obligation of the public sector, $F O P S_{\max }$, can be calculated, which is a sum of $P S C_{R A W}$ and discounted value of retained risk, Risk $_{r t n}$, transferred risk,

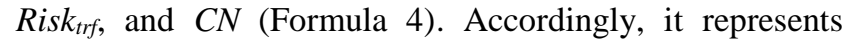
maximum obligations of the public sector in the PPP, above which PPP would not provide any financial benefits in respect of cost efficiency.

$$
F O P S_{\max }=P S C=P S C_{R A W}+\sum_{t=0}^{t=n} \frac{C N_{t}+\text { Risk }_{r t n_{t}}+\text { Risk }_{t r f_{t}}}{(1+r)^{t}}
$$

If wider social-economic approach is applied, NFBs and, if it is relevant to distinguish the perspective of the PPA, additional costs related to value-added tax (VAT) can be also included into the above-presented formula.

As the PSC, to be rational to compare, the PPP option also requires to be structuring according to the particular requirements. First, the scope of PPP in respect of transferred tasks has to be the same as the scope of PSC model. Second, the appropriate type and form of PPP has to be chosen. Here a line is usually drawn between the PPPs developed on the contractual basis and on the institutional basis, depending on the strategic importance and specificity of services foreseen to provide in the PPP. According to Batran, Essig, \& Schaefer (2004) and Duda (2010), if the specificity of services is low and the strategic importance is high, PPA has to establish the institutionalbased PPP as a distinct legal entity (SPV) created from both public and private capital. Conversely, if the specificity of public goods and services is high, while their strategic importance is low, then it is more expedient to established PPP on contractual basis. Third, considering PSC and the chosen basis of PPP, the appropriate form has to be chosen. In a case of the institutional-based PPP, it is available one form - basically it is a joint venture. While, in a case of the contract-based PPP the choice is wider. Forms of Management, Management and Operation, Leasing, Private finance Initiative (PFI), Concession with variety of schemes can be chosen accordingly. Forth, cost of PPP in respect of both the private entity and the PPA has to be calculated. In both cases the SB model consists of the same implicit cost elements: base cost, financing arrangement cost and ancillary cost accompanied by a risk retained by the PPA. If there are reasoned assumptions, cost reduction, due to integration of tasks and the private sector's innovation, can also be included into the assessment. However, it has also to be considered that, due to complexity of PPP, its transaction cost is usually higher. With only exception related to the retained risk and ancillary costs, the main difference between the abovementioned perspectives asserts in respect of time when the base cost is incurred by the PPA. From the perspective of the private entity, costs are incurred from the beginning of IP's implementation and are recognized when they actually occur (formula 5). While, from the perspective of the PPA, costs are usually incurred only when services are started to be delivered and are transformed into unitary availability payments required to be paid to the private entity throughout the periodo f PPP (formula 6).

$$
\begin{aligned}
& S B_{p r}=\sum_{t=0}^{t=n} \frac{B C_{t}+F A C_{t}+A C_{t}}{(1+r)^{t}}+\sum_{t=0}^{t=n} \frac{R_{i s k_{r t n_{t}}}}{(1+r)^{t}} \\
& B C_{t}=I_{t}-R E_{t}-R V_{n}+O M_{t}
\end{aligned}
$$

here: $B C$ - base cost, $A C$ - ancillary cost, which includes such cost as procurement and other transaction costs.

$$
\begin{aligned}
& S B_{p u}=\left(\sum_{t=0}^{t=n} \frac{U P_{t \geq m}}{(1+r)^{t \geq m}}\right)+\left(\sum_{t=0}^{t=n} \frac{R i s k_{r t n_{t}}+A C_{2}}{(1+r)^{t}}\right) \\
& U P \in\left(I-R E-R V+O M+F A C+A C_{1}\right) \\
& A C=A C_{1}+A C_{2}
\end{aligned}
$$

here: $U P$ - unitary payment, $\mathrm{AC}_{1}-$ ancillary cost of the bidder, $\mathrm{AC}_{2}$ - ancillary cost of the PPA.

The evaluation from the perspective of the private entity is needed to assess financial viability of PPP. Accordingly, it is viable, if requirements of all stakeholders are satisfied. The PPA requires at least a minimum level of equity, $R$, from the private entity and may require the appropriate minimum level of selffinancing ratio, $S F R$, to encourage right incentives from the private entity and decrease a demand of subsidies. The investors seek return on equity, IRRE. While, financiers or lenders seek to recover their debt and earn interests. If under equity holders' or/and lenders' requirements PPP is not financially viable and requires subsidies from the public sector, affordability of PPP from the perspective of the PPA also has to be assessed. Finally, PPP has to be financial sustainable and never run out money, i.e. cumulative CFs always have to be remained above zero. Accordingly, the optimization of PPP's financial structure can be considered as the system of the appropriate equations, where it has to be satisfied all the following conditions at required minimum level of equity: $R \geq R_{\min }$; $I R R E \geq I R R R_{\text {min }} ; R E P R \geq R E P R_{\text {min }} ; D S C R \geq D S C R_{\text {min }}$; $L L C R \geq L L C R_{\text {min }} ; P L C R \geq P L C R_{\text {min }} ; S F R \geq S F R_{\text {min }}$; $\operatorname{cum}\left(\mathrm{CI}_{i}-\mathrm{CO}_{i} \geq 0\right.$; Affordability - Yes.

If it is analyzed the possibility to implement IP as the institutional PPP, beside the above-presented optimization it is also important to determine an optimal structure of the public and private capital. According to Moszoro (2010), optimal share of the private capital in the $\operatorname{PPP}, \theta^{*}$, depends on such factors as capital expenditure required to satisfy the demand at the appropriate quality level $q, I(q)$, savings of expected capital expenditure (without financial costs) asserted due to a privately executed IP, $J(q)$, and ratio between cost of the private capital, $r_{p r}$, and the public capital, $r_{p u}$. The higher are savings and lower is the ratio between cost of capital, the higher share of the private capital is optimal in the PPP (formula 8).

$$
\theta^{*}=1-\frac{I(q)}{2 J(q)}\left(\frac{r_{p r}}{r_{p u}}-1\right)
$$

When both the PSC model and SB model are structured, very VfM assessment can be done, where the perspectives of the public sector, the PPA and users of public infrastructure and services are rational to distinguish. If the results of quantitative assessment do not show VfM, qualitative criteria can be rational to include in the assessment by using MCA. 
Stage 4. When the PPA gets the actual bids, it is relevant to assess whether they are still VfM, since they can significantly differ from what has been analyzed by the PPA in respect of demand prognosis, risk assessment, requirements for infrastructure, etc. If the actual bids significantly differ in respect of the main assumptions from PSC developed by the PPA, it can be rational also to adjust the PSC model accordingly to get relevant results of VfM assessment.

Stage 5. The quality of results of the assessment of PPP's possibilities to optimize investments in public infrastructure, especially in stages of initiation and procurement, highly depends on assumptions applied in the development of both the PSC and the SB. Therefore, when the PPP is established, it is important to collect data related to its actual implementation, which could be systemized and used as the empirically-grounded statistic to other assessment of possibilities and benefits of IPs to be implemented as PPP.

All the above-mentioned stages present the integrated complex approach to assessment of PPP's possibilities to optimize investments in public infrastructure.

\section{Description of the IPs}

The assessment of the created model's suitability to be used in solving the issues related to assessment of PPP's possibilities to optimize investments in public infrastructure was done on the hypothetical IP of new parking infrastructure's development, since this type of IPs, as a financial structure, can be very flexible in respect of financial mechanism and risk allocation that makes it suitable case study to accomplish this task. The IP includes the following inputs (Table 1).

Table 1

\section{Key Input Variables of the Hypothetical IP}

\begin{tabular}{ll} 
Economic data \\
\hline $2 \%$ & Inflation rate (energy, water, waste disposal: $3 \%)$ \\
Taxes & \\
\hline $21 \%$ & VAT \\
$15 \%$ & Profit tax \\
Project schedule \\
\hline 25 & Reference period for CFs calculation (number of years) \\
601 & Total days in construction period (design, construction of \\
& parking plots, installation of equipment) \\
8621 & Total days in operation period (O\&M, management) \\
13 & Year at which the medium repair is needed \\
21 & Year at which the major repair is needed \\
Capex & \\
\hline 2400 & Number of spaces built in multi-storey parking facility \\
600 & Number of spaces built in ground parking facility \\
150000 & Total design costs ( $€$ ) \\
20157600 & Total investment costs ( $€$ ) into the parking plots \\
151697 & Total investment costs ( $€$ ) into the parking equipment \\
Amortization and depreciation \\
\hline 15 & Depreciation period of garage infrastructure (year) \\
5 & Depreciation period of parking equipment (year) \\
Opex & \\
\hline 512849 & Annual operation costs \\
360000 & Cost of medium repair \\
1050000 & Cost of major repair \\
Revenue & \\
\hline 3431834 & Annual parking revenue ( \\
Loans & Term of permanent loan (years) \\
\hline 10 & Interest rate on loan during construction period \\
$3,0 \%$ & \\
\hline & \\
\hline
\end{tabular}

\section{Analysis of Results}

To demonstrate the possibilities of the created model to be applied in solving issues of the assessment of PPP's possibilities to optimize investments in public infrastructure, the hypothetical IP, as a case study, of which the key input variables have been presented in the previous section, was used. The created model consists of five stages. However, since they cover ex-ante assessment (stages 1-3), actual assessment (stage 4) and ex-post assessment (stage 5), only the first three stages, as the model is focused on the assessment of possibilities as the most complicated part of the assessment rather than the assessment of actual bids, have been included in the case study. This determines that the quantitative assessment is also prevailing.

To demonstrate the possibilities of model to be used under various conditions, the case study is divided into two basic scenarios. The main difference between them is focused on different risk allocation between the public and private entities, since this is one of the most important factor determining, which of the forms would be the most suitable to implement the IP as PPP. More specifically the difference reveals in respect of demand risk. In the first scenario, which represents the economic-based PPP model, most of demand risk is assumed by the private entity, which is reward by the right to collect revenues from the direct users. While, in the second scenario, which represents the social-based PPP model, on a contrary to the previous one all demand risk is assumed by the PPA, which pays to the private entity for infrastructure availability, while services are free of charge to the direct users. Each of the scenarios is further analyzed separately.

\section{Economic-Based PPP Model}

Stage 1. According to the model, to assess possibilities provided the PPP to optimize investments in public infrastructure at first there is a need to construct the CP option, rational to compare against any other option with appropriate involvement of private participation. Figure 3 shows returns on investments depending on the length of the IP's period, where FDR, considering formula 1, is equal to $6,2 \%$ (in a case of Lithuania). If the IP would be implemented in the traditional way, the payback period required to recover investment costs would be 11 years. This can be considered as a quite long period from the perspective of the private sector, however, since it is assumed that a price level is determined at a sociallyacceptable level, this can be acceptable from the perspective of the public sector. The figure illustrates that the longer a reference period is, the higher return indicators are, although the marginal growth, due to value of time, is significantly decreasing in the second part of the period. When the case of the 25 years' period is considering, NPV(I) and IRR(I), of which calculation is based on formula 8 , are equal to $21 \mathrm{~m}$ EUR and $15 \%$ respectively. 


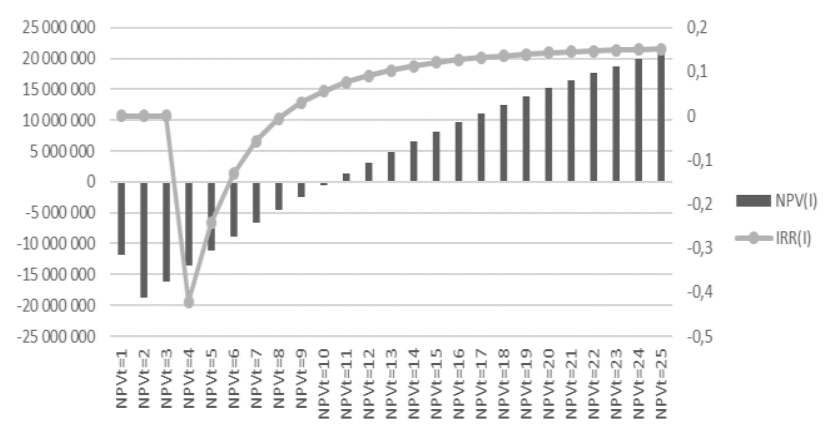

Figure 3. Risk Allocation in the PPP

Stage 2. This stage is committed to assess the potential of the developed IP to be implemented as PPP. Table 2 provides results of assessment, which are arranged in the same order as the above-provided list of criteria. Accordingly, they show that it is expedient to analyze the possibilities to implement the IP as PPP.

Table 2

Assessment for Satisfaction of Expediency Criteria

\begin{tabular}{|c|c|c|}
\hline No. & Y/N & Justification \\
\hline 1 & Y & 21,3 m EUR investments \\
\hline 2 & Y & 25 years \\
\hline 3 & Y & Integration of design, construction, O\&M tasks \\
\hline 4 & Y & Output specifications can be easily determined \\
\hline 5 & Y & Most of risk can transferred to the private sector \\
\hline 6 & Y & Direct users 'payments \\
\hline 7 & Y & $\begin{array}{c}\text { Market research revealed the existence of } \\
\text { interest from the private sector as well as } \\
\text { sufficient competition in the market }\end{array}$ \\
\hline
\end{tabular}

Stage 3. The PSC. This stage of the model starts with adjustment of the initial IP by risks, which are added to costs of initial CFs. Accordingly, risk value, of which calculation was done by applying the empirically-based PDs, provided by Jasiukevicius \& Vasiliauskaite, (2015), are 23,3 m EUR in the period of 25 years. Considering the above-provided model of risk allocation, total value of risk is shared between the private and public entities by proportion of $86 \%$ and $14 \%$, i.e. 20,1 m EUR and 3,2 m EUR respectively. Thus, the private entity would have to assume most of risks. Accordingly, FOPS max $_{\text {, of which }}$ calculation was based on formula 4, is equal to 5,2 m EUR, which can be considered as the maximum allowed obligations of the public sector in the PPP, above which PPP would be considered as ineffective in respect pf cot efficiency. Most of this sum consists of risk cost, since the IP is profitable itself and there are no payments needed to be paid to the private entity accordingly.

Since the public sector in the economic-based PPP can have the appropriate advantageous against the private entities in respect of tax payment, the taxes of land rent, asset and monitoring of PPP contract implementation, of which value is assumed to be equal to $2,9 \mathrm{~m}$ EUR at NPV have been additionally included as $\mathrm{NC}$ in this case.

To develop the PSC model, besides financial aspects, NFBs have also been included in the assessment. Accordingly, it was assumed that, due to a lack of public budget, the implementation of the IP would be delayed at least 3 years until PPA would be able to accumulate sufficient funding. The analysis of external social- economic impact disclosed that social-economic costs of inaccessibility of infrastructure are 1,7 m EUR at NPV.

Considering the above-calculated elements, costs of PSC have been calculated, of which general values and structure are presented in the Figure 4. It shows that, despite the IP becomes profitable from 11th year, when the values of risk and $\mathrm{CN}$ costs are included in calculation, total costs of PSC remain positive through the entire period of analysis. The line shows the threshold, above which PPP does not provide financial and social-economic benefit assessed in the quantitative assessment. In the period of 25 years any obligations of the public sector higher than 7,5 m EUR at NPV would be considered as an ineffective way to implement IP as PPP. Accordingly, this value calculated on different length of a period, are as benchmarks for further assessment of PPP's possibilities to optimize investment in public infrastructure.

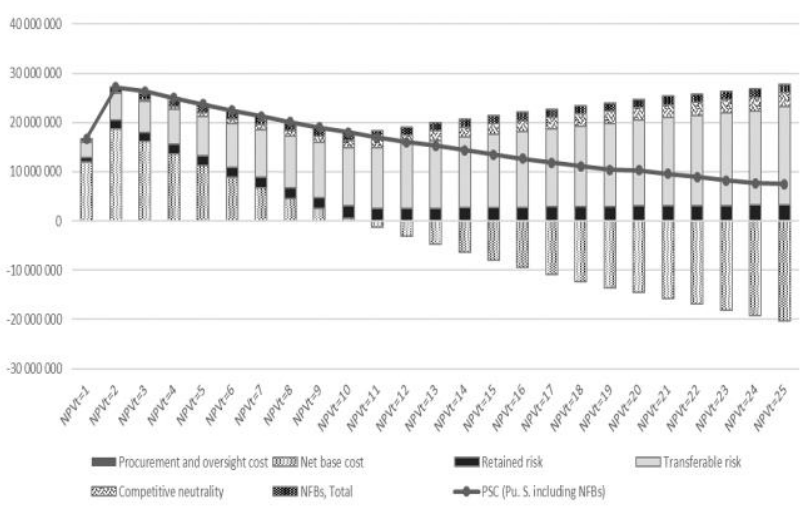

Figure 4. The Structure of PSC (Revenue Generating IP)

The SB model. According to the created model, to calculate obligations of the public sector in the PPP, which could be rationally compared against the PSC, there is a need to prepare the SB PPP model, characterized by the same scope of IP as in a case of the PSC model, however, taking into an account, that it is implemented by the private entity under the PPP contract, including tasks of design, construction, operation and maintenance of infrastructure, and the private entity is awarded to collect revenues from users for delivery of services. This requires at least a few additional assumptions. Accordingly, it was assumed that $70 \%$ of total capital investments is financed by loans and $60 \%$ of equity consists of subordinated debts, while other capital expenditures are financed by equity. Due to integration of tasks, cost savings of $10 \%$ was included in the SB model. Financial viability of PPP was assessed, considering the requirements of different stakeholders, provided in the Table 4.

Table 4

Satisfaction of Stakeholders' Requirements at Different Conditions (Revenues Generating IP)

\begin{tabular}{|c|c|c|c|c|c|}
\hline Indicator & $\begin{array}{c}\text { Min. } \\
\text { Req. }\end{array}$ & $\begin{array}{c}\text { Initial } \\
\text { situation }\end{array}$ & $\begin{array}{c}\text { MARF } \\
\text { competition }\end{array}$ & $\begin{array}{c}\text { Price } \\
\text { competition }\end{array}$ & $\begin{array}{c}\text { Monitoring } \\
\text { tax }\end{array}$ \\
\hline IRRE & $12,80 \%$ & $34,3 \%$ & $12,8 \%$ & $12,8 \%$ & $12,8 \%$ \\
\hline REPR & 0,30 & 0,3 & 0,3 & 0,3 & 0,3 \\
\hline DSCR & 1,30 & 1,91 & 1,37 & 1,37 & 1,41 \\
\hline LLCR & 1,50 & 6,59 & 4,58 & 4,58 & 4,72 \\
\hline PPCR & 5,00 & 15,22 & 9,96 & 9,96 & 10,66 \\
\hline SFA & 1,00 & 1,73 & 1,73 & 1,19 & 1,15 \\
\hline CCF & 0,00 & Yes & Yes & Yes & Yes \\
\hline
\end{tabular}


Considering the requirements from the stakeholders, Table 4 also provides the results of their satisfaction at the period of 25 years. The results disclosed that the SB model under the above-presented conditions is financially viable from the perspectives of all stakeholders, when the period is equal or longer than 8 years. From that year, all indicators become higher than the determined minimum level and are significantly growing as the period increases. On the one hand, this shows the IP as attractive for the market, since its return is higher than it is expected to get from the alternative investment options of the similar level of risk. On the other hand, this indicates that any longer period than 8 years determines the expected over profit that is not justified in respect of public interest. Therefore, the period should be shortening to 8 years or the appropriate conditions to the private entity, which could allow protecting the public interest, should be applied in the PPP.

Since the first option does not require significant changes and the assessment of PPP's possibilities to optimize investments in public infrastructure can be directly transferred to VfM assessment, the second one, to disclose more solutions for the practical issues related to this assessment, is continued in this case study. Accordingly, in this case, it is important to set conditions in the request for proposal (RFP), which would not allow getting over profit to the private entity.

If the competition between the investors in the market is high, it is possible to expect positive effect of market competition, if the price of service and marginal annual revenue flow (MARF), above which is shared by revenues with the PPA, are determined as the competitive criteria to select the most beneficial bid. Depending on weights on these criteria, the actual bids can be focused on these criteria accordingly, therefore the PPA should set them depending on the priorities.

If the PPA seeks to keep the same price level as e.g. it is determined in the appropriate area, then the strongest competition should be encouraging on MARF, which should be equal to nearly $0,73 \mathrm{~m}$ EUR at $40 \%$ of income sharing level with the PPA (lower than $50 \%$ was used considering recommendation of the revenue sharing provided by Yinglin Wang \& Liu (2015), in order to make the SB model financially viable at the period of 25 years and the risk of over profit would be decrease. If the priority is focused on price, when it is possible to expect $34 \%$ decrease of the price level. In both cases, the optimization was done by using the least square method.

However, if competition between the investors is low, then there is less chance that the market itself will adjust results of public procurement so that the above-mentioned lower price or higher MARF would be achieved. Therefore, it may be more expedient to set the PPP contract monitoring tax at the level, which could allow the PPA to determine the conditions for the equity investors, acceptable in respect of public interest. Accordingly, the monitoring tax should be increased to $940 \mathrm{k}$ EUR, i.e. increased by nearly 20 times.

Figure 5 shows the results of VfM when the SB model is prepared on the same conditions as in a case of the PSC. It allows stating that it is expedient to determine the length of period equal to 8 years, since from that year all requirements of stakeholders are satisfied and there is low risk that the private entity could get over profit. At that year VfM for the PPA, if NFBs are included in the assessment, is nearly 17,9 m EUR expressed in present value. While, VfM for the users, since the price level remains the same, is 1,7 $\mathrm{m}$ EUR, which is determined due to the assumption that PPP allows ensuring availability of infrastructure at least 3 years earlier.

Figure 6 shows the results of VFM when the conditions determined in the RFP encourage competition entirely on a level of MARF. If competition between the equity investors is strong, the PPA could expect to get revenues from the implementation of the PPP, which is equal to $40 \%$ of revenue above MARF. These revenues increase VfM to the PPA, which is equal to 19,5 m EUR and 15,1 $\mathrm{m}$ EUR higher in comparison with the case, when competition of MARF is not encouraged. VfM for users remains the same, since there are no changes related to the price level.

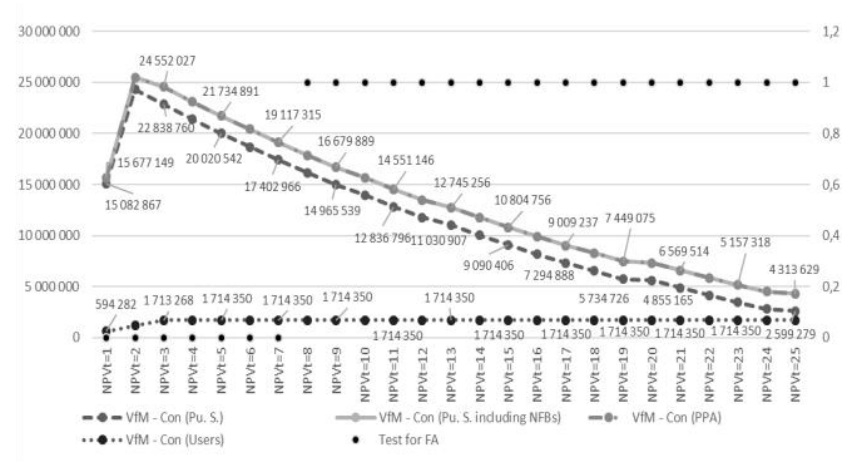

Figure 5. VfM and Financial Viability Assessment when the Same Assumptions are Applied as in a Case of PSC

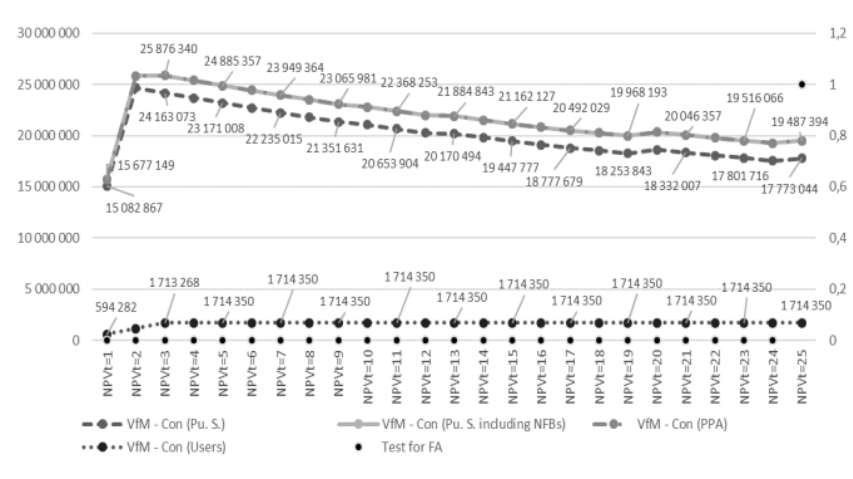

Figure 6. VfM and Financial Viability Assessment when Competition is Focused on the Level of MARF

Figure 7 shows the results of VFM when the conditions are determined to encourage competition entirely on the price. Since decrease of the price level is applied in both the PSC and SB model, VfM for the PPA also decreases to $16 \mathrm{~m}$ EUR, however, this increases VfM for the users. At the end of 25 years' period it is $17 \mathrm{~m} \mathrm{EUR}$ and consists of both benefits: decrease of price and earlier accessibility of services. Hence, the expected benefits for the users from the implementation of the IP as PPP are higher the benefits expected to get to the PPA. 
Accordingly, the comparison of this and earlier cases discloses possible interest conflict between the PPA and the users, since the PPA gets more benefit when the price level remains in same level in contrary to users, which prefer lower price level.

Finally, Figure 8 shows the results of VFM when the PPA, to determine conditions, which would protect public interests, sets the PPP monitoring tax at the appropriate level. Since the monitoring tax is not the object of competition, the revenue received from this tax is a guaranteed source of income that, in turn, increases VfM to the PPA. While, VfM to the users remains in the same level because the determined level of PPP monitoring tax does not leave possibilities for decreasing of the price level. This case shows that the PPA, to be insured, may determine tender conditions, which can be not acceptable to the users. Accordingly, the rational decision would be determined PPP monitoring tax at the level that also leaves possibilities for the price competition. The appropriate proportions have to be set depending on the particular project, market competition and the priorities of the PPA.

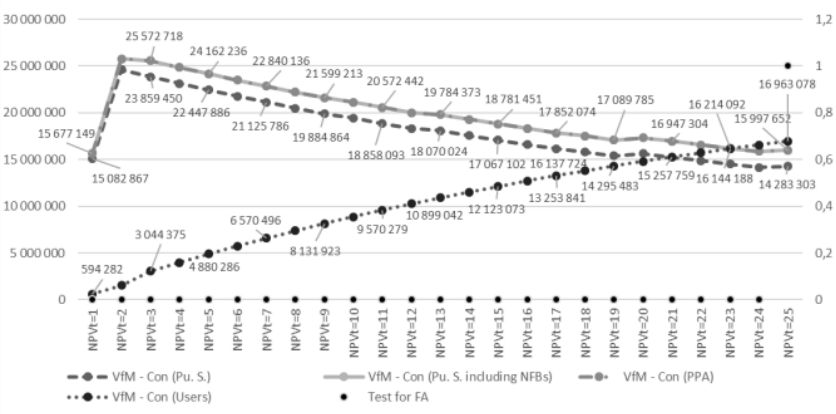

Figure 7. VfM and Financial Viability Assessment when Competition is Focused on the Price

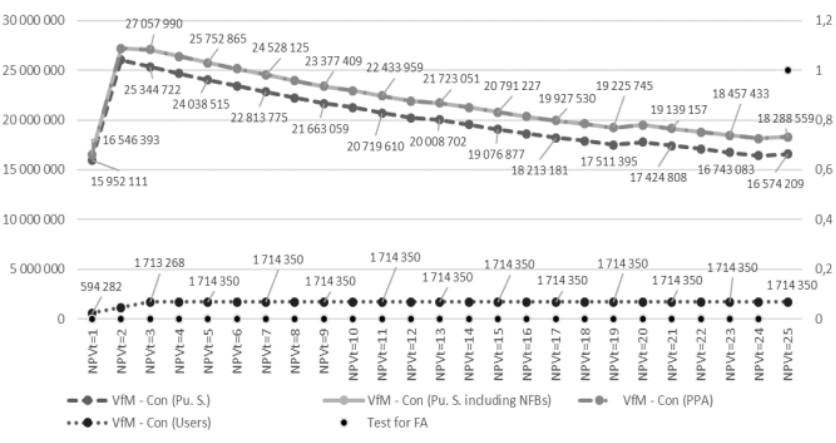

Figure 8. VfM and Financial Viability Assessment when PPP Contract Monitoring tax Increases

\section{Social-Based PPP Model}

To assess the possibilities of PPP to optimize investment in public infrastructure in the case of the socialbased PPP model, there are used the same initial key input variables as have been used in the previous scenario, except revenues are excluded from the analysis. Accordingly, since it is the non-revenue generated IP,
VAT of $21 \%$ is added on costs of capital investments and O\&M. Moreover, since the PPA has to cover all costs, it is expedient to release the private entity from taxes such as real estate, land rent and monitoring of PPP contract.

Stage 1. Since this is the non-revenue generating IP, all return indicators are negative. Accordingly, the longer is the period, the larger is costs. At the period of 25 years, $\mathrm{NPV}(\mathrm{I})$ is $-33,5 \mathrm{~m}$ EUR.

Stage 2. Since this scenario is the same IP as analyzed in the previous section, it satisfied the same expediency criteria for PPP potential. Only 6th criteria can be argued differently, that the private entity would be compensate for delivery of infrastructure and services by payments from the PPA, which will start to be paid, since the services will be available to the users.

Stage 3. Considering CFs of the IP, total risk value, calculated by applying the empirically-based PDs and their parameters, is $12,6 \mathrm{~m}$ EUR at NPV at the period of 25 years. In comparison with economic-based PPP model, it is lower than 11,3 m EUR, because, since services is free of charge, there is no revenue stream and, herewith, the risk, that changes of revenue stream could affect financial results of the IP. Therefore, despite of different allocation of demand RFs, i.e. the PPA bears more demand RFs in comparison with the economic-based PPP model, values of transferred and retained risks are shared in the similar proportion of $84 \%$ and $16 \%$ that is $10,5 \mathrm{~m}$ and $2 \mathrm{~m} \mathrm{EUR}$ respectively.

Structure of CFs determines that the longer the period is, the larger FOPS $_{\text {max }}$ is, because every additional year determines costs, which have to be covered by the PPA. In the period of 25 years they are equal to $46 \mathrm{~m}$ EUR.

Figure 9 shows the structure of PSC, which has been calculated considering the above-provided elements. Since costs related to VAT, as discussed in section 2.1.5., cannot be directly recovered as the revenue stream by the PPA, PSC of the PPA is higher by VAT, i.e. 6,3 m EUR than it would be calculated to the public sector. Accordingly, value of 47,7 m EUR expressed at NPV is the threshold above which tenders with larger obligations to the PPA in period of 25 years is considered as not giving any benefits in comparison with $\mathrm{CP}$ in the scope of the quantitative assessment. A little bit more than $60 \%$ of this amount consists of base costs, while other costs include procurement and oversight costs, VAT costs, risk costs and NFBs costs. In this case NFBs is the element determining the difference between FOPS $_{\max }$ and PSC.

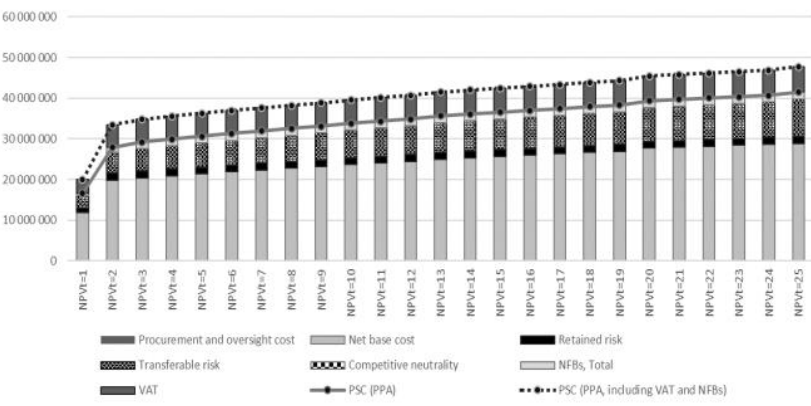

Figure 9. VfM and Financial Viability Assessment when PPP Contract Monitoring Tax Increases 
Considering the structured PSC and SB models, the Figure 10 shows the expected VfM for the PPA, the public sector and the users depending on the length of PPP period.

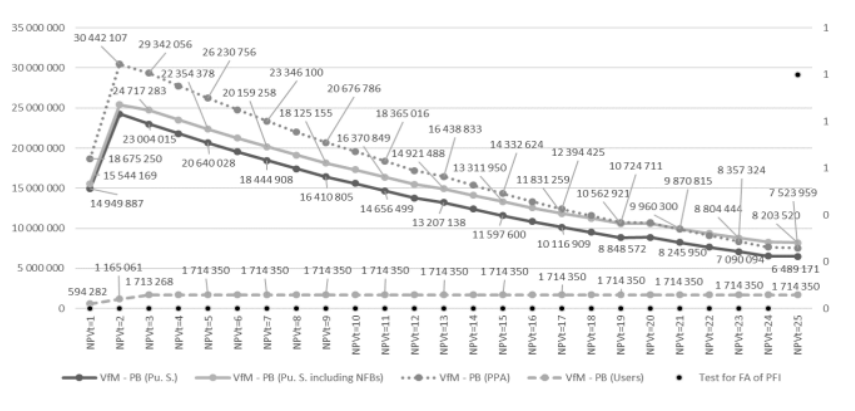

Figure 10. VfM and Financial Viability Assessment (Non-Revenue Generating IP)

It allows stating that PPP allows expecting to be more beneficial way of IP implementation than $\mathrm{CP}$, since VfM is reached from all three perspectives. The PPA gets the benefits from the lower financial and socio-economic costs, while the users from the earlier accessibility of infrastructure and services. Accordingly, VfM for the PPA is $7,5 \mathrm{~m}$ EUR, the public sector, for which VAT is not included in assessment, 8,2 m EUR and the PPA 1,7 m EUR, that is $16 \%, 20 \%$ and $16 \%$ respectively. This is more than the expected additional PPP's procurement costs (150 000 EUR) and the general accepted rate of $10 \%$.

\section{Conclusions}

The assessment of PPP's possibilities to optimize investments in public infrastructure includes many factors needed to be assessed and aspects needed to be considered, that makes it highly complex in nature. Theoretical analysis disclosed that VfM assessment is considered as a primary tool to assess benefits of IP's implementation as PPP. However, its results can be very different depending on the approach and assumptions applied. To get reliable results, both the rational public sector's model and the financially viable and affordable PPP model should be constructed as well as rational their comparison should be carried out, where VfM for different beneficiaries could be assessed.

To achieve the aim of the research, the model of PPP's possibilities to optimize investments in public infrastructure was created and, for disclosure of its potential to complexly solve the relevant issues related to this assessment, quantitatively tested in the hypothetical case study presenting both the social-based and economicbased scenarios. It consists of five stages, which cover both ex-ante and ex-post VfM assessment of IP's implementation as PPP. The model suggests a complex of solutions allowing not only to assess VfM in variously constructed PPPs, but also to maximize it, considering level of competition in the market, priorities of the public sector and beneficiaries, to which VfM can be calculated, as well as necessity to ensure financial viability of PPP and to assess its affordability to the public sector. Accordingly, the obtained results allow stating about the suitability of the model to overcome the issues realted to the assessment of PPP's possibilities to optimize investments in public infrastructure and make reasoned decisions for the most efficient ways of public IP's implementation.

Since the model enables to simulate various cases of collaboration between the public and private entities, besides its practical purpose, it can be also used for further investigations related to the collaboration of the public and private sectors in the context of project finance: determination of the optimal structure of payment mechanism and government guarantees to the private entities participating in the PPP and determination of the typical created model's parameters for groups of the typical IPs. The first one is perspective for determination of financial conditions encouraging right incentives from the private entities in PPPs as well as defending the interests of the PPA, and the users. While, the second one would allow standardizing these conditions, which, in turn, would facilitate the very assessment of PPP's possibilities to optimize investments in public infrastructure in the various economic sectors.

\section{References}

Abednego, M. P., \& Ogunlana, S. O. (2006). Good project governance for proper risk allocation in public-private partnerships in Indonesia. International Journal of Project Management, 24, 622-634. https://doi.org/10.1016/j.ij proman.2006.07.010

Ball, R. (2011). Provision of public service infrastructure - the use of PPPs in the UK and Australia: A comparative study. International Journal of Public Sector Management, 24, 5-22. https://doi.org/10.1108/09513551111099190

Bao, H., Peng, Y., Ablanedo-Rosas, J. H., \& Gao, H. (2014). An alternative incomplete information bargaining model for identifying the reasonable concession period of a BOT project. International Journal of Project Management, 33(5), 1151-1159. https://doi.org/10.1016/j.ijproman.2014.12.004

Batran, A., Essig, M., \& Schaefer, B. (2004). Public-Private Partnerships as an Element of Public Procurement Reform in Germany. International Public Procurement Conference, 127-149. http://doi.org/0-9668864-1-0

Bednarek, Z., Moszoro, M., Chen, B. L., Liou, F. M., Huang, C. P., \& Moszoro, M. (2012). Optimal Financing Mix of Financially Non-Viable Private-Participation Investment Project with Initial Subsidy. Inzinerine EkonomikaEngineering Economics, 23(5), 452-461. https://doi.org/10.5755/j01.ee.23.5.3130 
Linas Jasiukevicius, Asta Vasiliauskaite. The Assessment of Public-Private Partnership’s Possibilities to Optimize Investments...

Burke, R., \& Demirag, I. (2015). Changing perceptions on PPP games: Demand risk in Irish roads. Critical Perspectives on Accounting, 27, 189-208. https://doi.org/10.1016/j.cpa.2013.11.002

Carbonara, N., Costantino, N., \& Pellegrino, R. (2014). Concession period for PPPs: A win-win model for a fair risk sharing. International Journal of Project Management, 32(7), 1223-1232. https://doi.org/10.1016/j.ijproman. 2014.01.007

Chung, D., Hensher, D. a., \& Rose, J. M. (2010). Toward the betterment of risk allocation: Investigating risk perceptions of Australian stakeholder groups to public-private-partnership tollroad projects. Research in Transportation Economics, 30(1), 43-58. https://doi.org/10.1016/j.retrec.2010.10.007

Copeland, B. L. (2014). A History of the Equity Risk Premium and Its Estimation.

Desgrees du Lou, A. (2012). Value for Money evaluation in PPPs: difficulties and developments. Degree Project, 1-96.

Duda, M. (2010). Teoriniai viesojo ir privataus sektoriu partnerystes igyvendinimo aspektai. Viesoji Politika Ir Administravimas, 2603(33), 139-151. Retrieved from http://www.ktu.lt/lt/mokslas/zurnalai/vpa/vpa33/139-151.pdf

Evans, D. (2009). Uncertainty and social discounting for the very long term. Journal of Economic Studies, 36(1997), 522540. https://doi.org/10.1108/01443580910992429

Fernandes, C., Ferreira, M., \& Moura, F. (2015). PPPs — True Financial Costs and Hidden Returns. Transport Reviews, 36(2), 207-227. https://doi.org/10.1080/01441647.2015.1076905

Gordon, C., Mulley, C., Stevens, N., \& Daniels, R. (2013). How optimal was the Sydney Metro contract?: Comparison with international best practice. Research in Transportation Economics, 39, $239-246$. https://doi.org/10.1016/j.retrec.2012.06.020

Gouveia, M., \& Raposo, P. (2012). The Public Sector Comparator of PPP: An empirical evaluation in the Healthcare Sector. Incomplete, $\mathrm{x}(\mathrm{x}), 1-21$.

Gozen, M. (2013). Cost of Equity Estimation for Energy Network Utilities in Emerging Economies: A Comprehensive Review. Journal of Alanya Faculty of Business, 5(3), 63-72. Retrieved from http://alanyadergi.akdeniz.ed u.tr/_dinamik/164/439.pdf

Grimsey, D., \& Lewis, M. K. (2004). Discount debates: Rates, risk, uncertainty and value for money in PPPs. Public Infrastructure Bulletin, 1(3), 3-8.

Grimsey, D., \& Lewis, M. K. (2005). Are Public Private Partnerships value for money? Evaluating alternative approaches and comparing academic and practitioner views. Accounting Forum, 29, $345-378$. https://doi.org/10.1016/j.accfor.2005.01.001

Gupta, A., Gupta, M. C., \& Agrawal, R. (2013). Identification and ranking of critical success factors for BOT projects in India. Management Research Review, 36(11), 1040-1060. https://doi.org/10.1108/MRR-03-2012-0051

Hall, D. (2008). PPPs in the EU: a critical appraisal. ASPE Conference St. Petersburg, 44(0), 1-32. Retrieved from http://www.psiru.org/reports/2008-11-PPPs-crit.doc

Hanak, T., \& Muchova, P. (2015). Impact of Competition on Prices in Public Sector Procurement. Procedia Computer Science, 64, 729-735. https://doi.org/10.1016/j.procs.2015.08.601

Hanaoka, S., \& Palapus, H. P. (2012). Reasonable concession period for build-operate-transfer road projects in the Philippines. International Journal of Project Management, 30(8), 938-949. https://doi.org/10.1016/ j.ijproman.2012.02.001

Harvey, C. R. (2005). 12 Ways to Calculate the International Cost of Capital. Working Paper, 1-20.

Hellowell, M. (2013). PFI redux? Assessing a new model for financing hospitals. Health Policy, 113(1-2), 7785.https://doi.org/10.1016/j.healthpol.2013.09.008

Hwang, B. G., Zhao, X., \& Gay, M. J. S. (2013). Public private partnership projects in Singapore: Factors, critical risks and preferred risk allocation from the perspective of contractors. International Journal of Project Management, 31(3), 424-433.https://doi.org/10.1016/j.ijproman.2012.08.003

Jasiukevicius, L., \& Vasiliauskaite, A. (2015). Cost overrun risk assessment in the public investment projects: an empirically- grounded research. Inzinerine Ekonomika-Engineering Economics, 26(3), accepted to publish. https://doi.org/10.5755/j01.ee.26.3.8631

Jin, X.-H., \& Zhang, G. (2011). Modelling optimal risk allocation in PPP projects using artificial neural networks. International Journal of Project Management, 29(5), 591-603. https://doi.org/10.1016/j.ijproman.2010.07.011 
Ke, Y., Wang, S., Chan, A. P. C., \& Lam, P. T. I. (2010). Preferred risk allocation in China's public-private partnership (PPP) projects. International Journal of Project Management, 28(5), 482-492. https://doi.org/10.1016/j.ijp roman.2009.08.007

Khadaroo, I. (2008). The actual evaluation of school PFI bids for value for money in the UK public sector. Critical Perspectives on Accounting, 19, 1321-1345. https://doi.org/10.1016/j.cpa.2007.05.001

Kokkaew, N., \& Wipulanusat, W. (2014). Completion delay risk management: A dynamic risk insurance approach. KSCE Journal of Civil Engineering, 18(6), 1599-1608. https://doi.org/10.1007/s12205-014-1128-4

Lehtiranta, L. (2014). Risk perceptions and approaches in multi-organizations: A research review $2000-2012$. International Journal of Project Management, 32(4), 640-653. https://doi.org/10.1016/j.ijproman.2013.09.002

Liu, J., Love, P. E. D., Smith, J., Regan, M., \& Palaneeswaran, E. (2015). Review of performance measurement: implications for public-private partnerships. Built Environment Project and Asset Management, 5(1), 35-51. https://doi.org/10.1108/02683940010305270

Marcelin, I., \& Mathur, I. (2014). Privatization, financial development, property rights and growth. Journal of Banking \& Finance, 50, 528-546. https://doi.org/10.1016/j.jbankfin.2014.03.034

Martins, A. C., Marques, R. C., \& Cruz, C. O. (2011). Public-private partnerships for wind power generation: The Portuguese case. Energy Policy, 39(1), 94-104. https://doi.org/10.1016/j.enpol.2010.09.017

Maskin, E., \& Tirole, J. (2008). Public-private partnerships and government spending limits. International Journal of Industrial Organization, 26, 412-420. https://doi.org/10.1016/j.ijindorg.2007.05.004

Moro Visconti, R. (2014). Improving Value for Money in Italian Project Finance. Managerial Finance, 40(11), 10581077. https://doi.org/10.1108/MF-07-2013-0171

Moszoro, M. (2010). A Theory of Efficient Public-Private Capital Structures. IMF Working Paper, (February), 1-23.

Moszoro, M. (2014). Efficient public-private capital structures. Annals of Public and Cooperative Economics, 85(1), 103126. https://doi.org/10.1111/apce. 12028

Mota, J., \& Moreira, A. C. (2015). The importance of non-financial determinants on public-private partnerships in Europe. International Journal of Project Management, 33(7), 1563-1575. https://doi.org/10.1016/j.ijproman.2015.04.005

Mu, R., Jong, M. De, \& Koppenjan, J. (2011). The rise and fall of Public-Private Partnerships in China: a path-dependent approach. Journal of Transport Geography, 19(4), 794-806. https://doi.org/10.1016/j.jtrangeo.2010.10.002

Muller, R., \& Turner, J. R. (2005). The impact of principal-agent relationship and contract type on communication between project owner and manager. International Journal of Project Management, 23(5 SPEC. ISS.), $398-403$. https://doi.org/10.1016/j.ijproman.2005.03.001

Ng, S. T., Wong, Y. M. W., \& Wong, J. M. W. (2012). Factors influencing the success of PPP at feasibility stage - A tripartite comparison study in Hong Kong. Habitat International, 36(4), 423-432. https://doi.org/10.1016/j.h abitatint.2012.02.002

Ng, S. T., Xie, J., Cheung, Y. K., \& Jefferies, M. (2007). A simulation model for optimizing the concession period of public-private partnerships schemes. International Journal of Project Management, 25, $791-798$. https://doi.org/10.1016/j.ijproman.2007.05.004

Okmen, O., \& Oztas, A. (2010). Construction cost analysis under uncertainty with correlated cost risk analysis model. Construction Management and Economics, 28(November 2013), 203-212. https://doi.org/10.1080/0144 6190903468923

Parker, D., \& Hartley, K. (2003). Transaction costs, relational contracting and public private partnerships: A case study of UK defence. Journal of Purchasing and Supply Management, 9, 97-108. https://doi.org/10.1016/S09697012(02)00035-7

Sarmento, J. M., \& Renneboog, L. (2016). Anatomy of public-private partnerships: their creation, financing and renegotions. International Journal of Managing Projects in Business, 9(2), 94-122. https://doi.org/10.1108/17538370810883819

Shaoul, J. (2005). A critical financial analysis of the Private Finance Initiative: Selecting a financing method or allocating economic wealth? Critical Perspectives on Accounting, 16, 441-471. https://doi.org/10.1016/j.cpa.2003.06.001

Silvestre, H. C. (2012). Public-private partnership and corporate public sector organizations: Alternative ways to increase social performance in the Portuguese water sector? Utilities Policy, 22, 41-49. https://doi.org/10.1016/ j.jup.2012.01.002

Takashima, R., Yagi, K., \& Takamori, H. (2010). Government guarantees and risk sharing in public-private partnerships. Review of Financial Economics, 19(2), 78-83. https://doi.org/10.1016/j.rfe.2009.10.001 
Linas Jasiukevicius, Asta Vasiliauskaite. The Assessment of Public-Private Partnership's Possibilities to Optimize Investments...

Tirelli, M. (2006). The evaluation of public investments under uncertainty. Research in Economics, 60, $188-198$. https://doi.org/10.1016/j.rie.2006.10.001

Tsamboulas, D., Verma, A., \& Moraiti, P. (2013). Transport infrastructure provision and operations: Why should governments choose private-public partnership? Research in Transportation Economics, 38, $122-127$. https://doi.org/10.1016/j.retrec.2012.05.004

Villalba-Romero, F., \& Liyanage, C. (2016). Implications of the use of different payment models. The context of PPP road projects in the UK. International Journal of Managing Projects in Business, 9(1), 11-32. https://doi.org/10. $1108 / 17538370810883819$

Wang, E. C. (2002). Public infrastructure and economic growth: A new approach applied to East Asian economies. Journal of Policy Modeling, 24, 411-435. https://doi.org/10.1016/S0161-8938(02)00123-0

Wang, Y., \& Liu, J. (2015). Evaluation of the excess revenue sharing ratio in PPP projects using principal-agent models. International Journal of Project Management, 33(6), 1317-1324. https://doi.org/10.1016/j.ijproman.2015.03.002

Wang, N. (2014). Private finance initiative as a new way to manage public facilities. Facilities, 32(11/12), 584-605. https://doi.org/10.1108/F-09-2012-0069

Wibowo, A., Permana, A., Kochendorfen, B., Kiong, R. T. L., Jacob, D., \& Neunzehn, D. (2012). Modeling Contingesnt Liabilities Arising from Government Guarantess in Indonesian BOT/PPP Toll Roads. Journal of Comparative Economics, 138(12), 1403-1410. https://doi.org/10.1061/(ASCE)CO.1943-7862.0000555

Zawawi, N. A. W. A., Ahmad, M., Umar, A., Khamidi, M. F., \& Idrus, A. (2014). Financing PF2 Projects: Opportunities for Islamic Project Finance. Procedia Engineering, 77, 179-187. https://doi.org/10.1016/j.proeng.2014.07.015

Zhang, X. (2005). Financial viability analysis and capital structure optimization in privatized public infrastructure projects. Journal of Construction Engineering and Management, 131(6), 656-668. https://doi.org/10.1061/(ASCE)07339364(2005)131:6(656)

Zhang, X., \& Chen, S. (2013). A systematic framework for infrastructure development through public private partnerships. IATSS Research, 36(2), 88-97. https://doi.org/10.1016/j.iatssr.2012.11.001

The article has been reviewed.

Received in September, 2017; accepted in February, 2018. 